\title{
DESIGN DE SERVICOOS PARA UMA EXPERIÊNCIA SIGNIFICATIVA NA REVITALIZAÇÃO DE UM CINEMA DE RUA
}

Service design for a significant experience by the revitalization of a classic street theater

SANTOS, Vivian dos

Universidade Feevale

vih.vivian@gmail.com

COSSIO, Gustavo

Universidade Feevale

cossio@feevale.br

\section{Resumo}

Resumo: Nesse trabalho pretende-se propor uma experiência envolvente na revitalização de um cinema de rua que existiu na cidade de Novo Hamburgo - Rio Grande do Sul. O cinema em estudo, o Cine Lumière, era o maior do interior do estado entre 1950 e 1980. Por meio do design de serviços, o objetivo foi apontar possibilidades para resgatar o espaço e oferecer à população atual uma alternativa de lazer e cultura distinta em relação ao modelo dos cinemas contemporâneos.

Palavras-chave: design de serviços, design para experiência, design e cultura, cinema de rua.

\section{Abstract}

CAbstract: This work aims to propose an engaging experience by the revitalization of a street movie theater that existed in the city of Novo Hamburgo - Rio Grande do Sul. The movie theater under study Cine Lumière was known as the largest theater in the countryside from the 1950s to the 1980s. Through service design, the aim is to offer an alternative of leisure and culture distinct from the model of contemporary cinemas.

Key-words: service design, experience design, design and culture, street movie theater. 


\section{INTRODUĈ̣̃O}

O tema em estudo caracteriza-se pela influência do design de serviços na revitalização de um sistema-produto de entretenimento, tendo em vista o resgate de um cinema de rua enquanto patrimônio cultural, o Cine Lumière, existente na cidade de Novo Hamburgo - RS, entre 1954 e 1982. Desse modo, tem-se como objetivo geral investigar e projetar um serviço no contexto de atendimento do cinema que proporcione uma experiência singular e envolvente aos seus frequentadores. Para tanto, serão considerados os respectivos objetivos específicos: a) apontar características relevantes para o desenvolvimento de um sistema-produto que resgate a experiência do cinema de rua junto aos frequentadores; b) analisar a interação entre o usuário e o ambiente de atendimento e indicar como o serviço prestado pode ser mais envolvente; $c$ ) pesquisar elementos que contribuam para que o ambiente do cinema promova a socialização entre os espectadores e uma permanência agradável no espaço; d) apontar possibilidades de serviços personalizados direcionados ao cinema de rua visando, por meio do resgate do patrimônio histórico, oferecer uma alternativa de entretenimento distinta à proporcionada nas salas de exibição dos shopping centers de hoje.

Com os objetivos citados, pretende-se responder ao problema de pesquisa: como o design de serviços direcionado à revitalização de um cinema de rua pode proporcionar uma experiência agradável, memorável e envolvente para a população de Novo Hamburgo e região do Vale dos Sinos? A partir da problemática levantada, pode-se lançar as seguintes hipóteses: a) os frequentadores de cinema apreciam que o atendimento seja organizado, rápido e que seja versátil; b) o que atrai o usuário a determinado serviço é a eficiência em atender suas necessidades e proporcionar benefícios diferenciados em relação à concorrência; c) além de suprir os interesses do cliente, um serviço voltado para o entretenimento deve surpreender e promover experiências memoráveis, e o desenvolvimento de projeto em design com enfoque na valorização do patrimônio histórico contribui para o fortalecimento da identidade cultural e territorial.

Como justificativa para esse projeto, é relevante mencionar o fato do design de serviços ser uma abordagem recente no campo do design - "a disciplina ganhou espaço acadêmico em 1994 e atingiu o mercado em meados de 2001" (PINHEIRO e ALT, 2012, p. 134). Com isso, constata-se a oportunidade de abordar a temática em uma pesquisa com enfoque teórico-prático. Para tanto, foi escolhido o ambiente de entretenimento do cinema, com a intenção de compreender como o design pode influenciar em um serviço cuja principal expectativa é a experiência.

No que se refere à experiência nos cinemas atualmente - cuja maioria

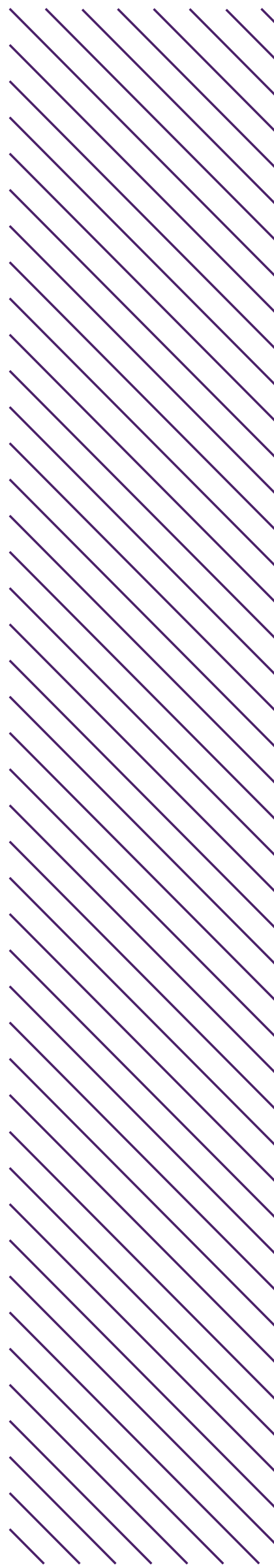


está instalada em shopping centers - é possível observar que os ambientes de atendimento não apresentam uma variação significativa que proporcione diferenciação entre os ambientes. Do mesmo modo, é visto que esses ambientes não são projetados para uma experiência cativante e singular, o que não contribui para que o público possa criar um vínculo com determinado serviço e espaço.

Outro fator relevante para a pesquisa consiste no fato de que atualmente os clientes estão cada vez mais interessados em experiências, além de bens de consumo tradicionais. Em contrapartida, as pessoas, cada vez mais, estão limitando o entretenimento ao interior de suas casas. Seja pela comodidade ou pela segurança, se limitam ao uso de eletroeletrônicos e perdem a oportunidade de socializar, de terem novas vivências, de estar e fazer algo. Destaca-se também a necessidade de pertencimento, o que faz com que as pessoas busquem laços com o local onde vivem. Neste aspecto, a proposta de resgatar a experiência do cinema de rua é estratégica para suprir a demanda por espaços de socialização na cidade, ao passo que pode contribuir para fortalecer a identidade local. Pelo estudo de um espaço que foi palco de tantas vivências no passado, pretende-se propor uma alternativa de lazer e socialização no presente.

\section{DESENVOLVIMENTO}

A partir do problema de pesquisa pretendeu-se, através da fundamentação teórica sobre design de serviços, analisar o contexto do cinema, abrangendo as peculiaridades do serviço prestado no segmento de salas exibidoras, das características dos ambientes e as expectativas por parte dos frequentadores. Com o método de trabalho, buscou-se apresentar opções de serviços que visam atender a demanda do público por uma experiência significativa. Esses princípios serão abordados a seguir.

\subsection{Design de serviços para uma experiência significativa}

O design de serviços tem como objetivo criar os detalhes da interação do cliente durante sua jornada no serviço. Para tanto, faz uso de métodos e ferramentas que possibilitam fazer a experiência de serviço consistente, desejável, útil e viável (COSTA, 2008; MORITZ, 2005). Através dos conhecimentos integrados de gestão, marketing, pesquisa e design, Moritz (2005) destaca que, o design de serviços combina as melhores ferramentas para, conectar a organização ao cliente e enfrentar os desafios do mercado. A relação entre as áreas de estudo que caracterizam o design de serviços pode ser vista na figura 01. 
Figura 01 - Design de serviços: áreas de conhecimento

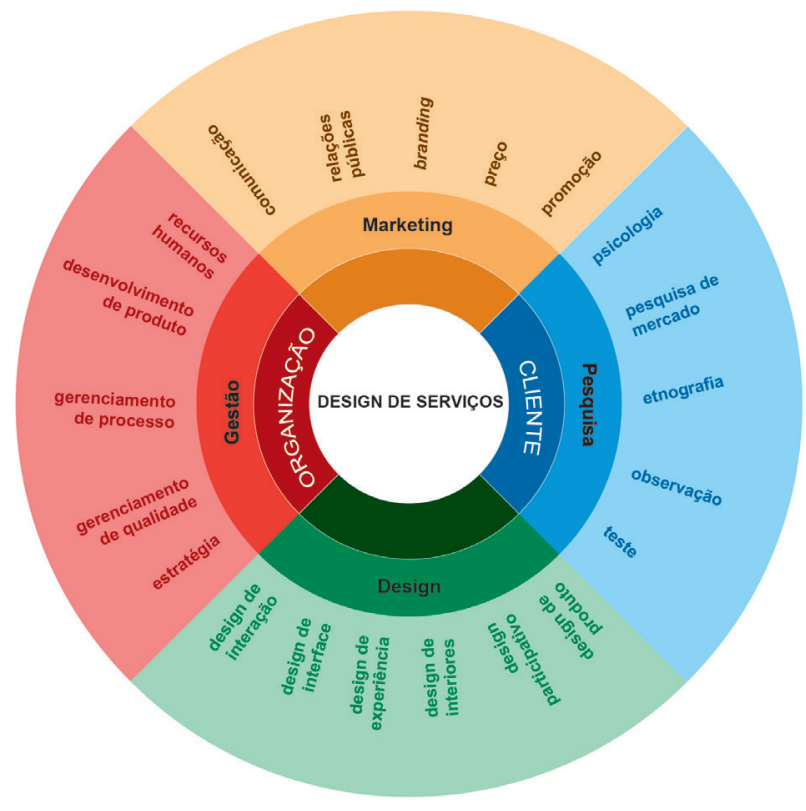

Fonte: elaborado pela autora, adaptado de Moritz (2005).

Nesse trabalho, serão contemplados com maior ênfase os campos da área do design, além dos relacionados à pesquisa centrada no usuário. A seguir, são descritas cada uma das especialidades conforme o autor, bem como, sua relevância para esse projeto.

O design de interação analisa o comportamento do usuário na interação com dispositivos e sistemas em espaços físicos e virtuais. Tem como objetivo a criação de um sistema que pode ser compreendido e usado por clientes de uma maneira simples e eficiente. No design de serviços, tem a finalidade de projetar os sistemas, caminhos e interações dos clientes em cada ponto de contato. Já o design de interfaces trabalha no projeto de máquinas e interfaces de produto. No design de serviços atua no desenvolvimento de dispositivos digitais. $\mathrm{Na}$ proposta desse projeto, os dois campos foram considerados na automatização de processos para facilitar as interações dos clientes com os pontos de contato .

Mesmo para serviços que não incluem a obtenção de nenhum bem material, os princípios do design de produto podem auxiliar no desenvolvimento de interfaces tangíveis e no projeto de embalagens. Já o design de interiores pode contribuir na definição do tom e da expectativa dos clientes em relação ao ambiente de serviço. No projeto de revitalização do cinema em estudo, foram utilizadas técnicas do design de interiores postuladas por Miriam Gurgel (2010), para construir os espaços do cinema de maneira integrada e com artefatos de interação que pretendessem atender às expectativas.

No design participativo, o cliente é colaborador ativo do processo, o que

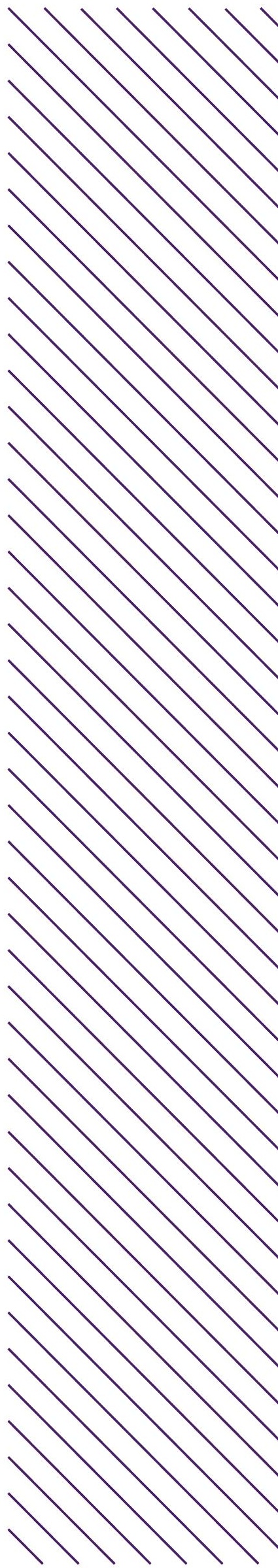


viabiliza a co-criação de projetos. Na área de serviços, este método possibilita maior aproximação e compreensão das necessidades do usuário. O design participativo foi contemplado através das sessões de workshop realizadas com projetistas e cinéfilos.

Por sua vez, o design para experiência, foco desse trabalho, tem como finalidade proporcionar experiências bem sucedidas aos clientes. As experiências podem ser projetadas utilizando qualquer meio, ambiente, produtos, serviços, imagens e sons, performances ao vivo, eventos, mídia impressa e digital. Portanto, a atividade se ocupa em projetar de maneira integrada as interações dinâmicas com objetos, espaços e serviços, promovendo qualidade na experiência do usuário através de soluções culturalmente relevantes (SURI, 2003; RIOS, 2011).

Segundo Limeira (2008), as experiências são subjetivas devido ao caráter multissensorial, podendo provocar reações de natureza fisiológica (suor, frio, tontura, choro, riso, dor, etc.) e psicológica (sentimentos de alegria, paixão, raiva, angústia, tristeza, medo, etc.). Savastano (2008) complementa, determinando que os atributos da experiência são qualquer conjunto de estímulos que apele aos sentidos (visão, olfato, paladar, tato e audição) - quando há envolvimento físico -, aos sentimentos - quando há envolvimento emocional -, ou ao intelecto - quando há envolvimento mental. Hekkert (2006), apresenta conceito semelhante ao definir que a experiência de uma pessoa com um produto pode ser estética - quando todos os sentidos são gratificados; de significado - quando são apegados significados ao objeto; e emocional - quando sentimentos e emoções são evocados.

O principal diferencial do consumo de entretenimento é a natureza intangível e hedonista - capaz de oferecer simbologia, prazer, conhecimento, memórias e sensações. É, sobretudo, consumo de experiência. Na formatação do produto do entretenimento deve-se ter clareza e controle de quais benefícios, experiências ou sensações cada um dos estímulos está oferecendo e se o conjunto destes atributos é superior à concorrência. $O$ entretenimento deve ser concebido como espetáculo, não para criar ilusão, mas para permitir que as sensações sejam realistas, envolventes e intensas. Neste contexto, o objetivo da experiência de consumo é sempre engajar o público criativamente e envolver e estimular as pessoas a participar e interagir com os outros indivíduos (ROCHA; BARROS; KARAM, 2012; SAVASTANO, 2008; LIMEIRA, 2008).

Os autores enfatizam que as reações ao consumo de experiências são pessoais e únicas. Porém, através da compreensão dos aspectos cognitivos pelos quais elas ocorrem, é possível projetar estímulos que proporcionem experiências positivas, por meio do design para a experiência (SAVASTANO, 2008; RIOS, 2011). Com isso, nesse trabalho pretendeu-se ampliar a 
permanência no cinema, sobretudo atuando no serviço de atendimento. Abaixo, a pesquisa histórica complementa o quadro teórico, tendo em vista o resgate do cinema de rua em Novo Hamburgo, e o estudo dos parâmetros necessários para uma experiência significativa.

\subsection{Os cinemas de rua de Novo Hamburgo}

Na cidade de Novo Hamburgo - local em estudo nesse trabalho - o primeiro registro de um cinema no município data de 1913, quando Adão Adolfo Schmitt alugou o salão de sua casa para projetar filmes. Anos depois, Sara Lanzer, proprietária de uma casa de comércio, mandou construir uma sala de projeções com o valor recebido de um prêmio de loteria. A sala que foi aberta na Avenida Maurício Cardoso, no bairro Hamburgo Velho, inicialmente recebeu o nome de Cinema Central. No entanto, após ser comprada por Lothário Blankenheim passou a ser o Cine Aída.

Nos anos que se seguiram, a família Blankenheim e a empresa Jaeger \& Venturini Ltda. foram os responsáveis pela abertura dos outros três cinemas que a cidade recebeu, estes localizados no centro. Por volta de 1930, foi inaugurado o Cinema Guarani, na Avenida Pedro Adams Filho, que em 1960 passou a se chamar Cine Avenida. Neste período, também já havia o Cine Carlos Gomes, na rua Lima e Silva, propriedade dos Blankenheim. Por último, foi inaugurado o Cine Lumière, no dia 1ำ de maio de 1954. A grande sala de espetáculos tinha capacidade para cerca de 1718 pessoas. O prédio que foi construído na Rua General Neto possui aproximadamente $1531 \mathrm{ml}$, com isso, o cinema era considerado o maior do interior do estado. Assim como em outras localidades do país,

\begin{abstract}
os eventos, ocorridos nos quatro cineteatros existentes na cidade, frequentemente geravam grandes filas e despertavam o interesse de diferentes atores sociais, servindo de espaço de convivência para as mais diversas manifestações culturais, pois, além das sessões cinematográficas, serviam de espaço para apresentações teatrais, festivais de música, show de orquestras, corais etc (SILVA; PUHL; STRÖHER, 2009, p. 48).
\end{abstract}

No entanto, entre as décadas de 1950 e 1970 os cinemas de rua passaram a sofrer com a diminuição de público, devida, entre outros fatores, à popularização da televisão. Uma resposta a essa crise foi a busca de aperfeiçoamentos na qualidade de imagem e som a fim de atrair os espectadores. Em 1980, teve início a migração das salas para os shopping centers. Sobretudo nos cinemas projetados na década de 1990, optou-se por um padrão de ambiente mais

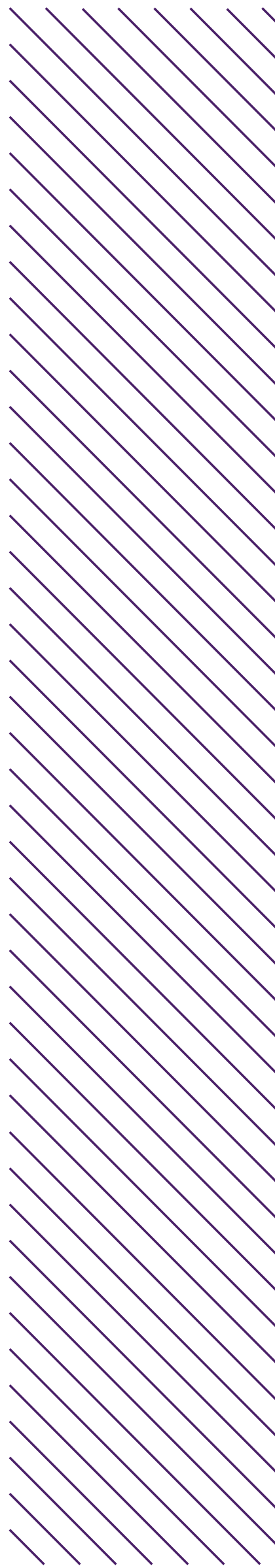


compacto, porém com telas mais amplas e som e imagens digitais, modelo conhecido como multiplex. Os cinemas no interior dos shoppings minimizavam a sensação de insegurança provocada pela violência presente nos centros das grandes cidades (TAVARES, 2010). Porém, conforme afirma Turner (1997), o próprio formato multiplex afastou parte dos espectadores das salas devido à segmentação do mercado. Com a fragmentação em unidades menores, o cinema, que antes contemplava o mercado de massa, passou a ser direcionado ao público jovem.

Em vista disso, os grandes palácios de exibição, que tradicionalmente faziam parte da identidade cultural das cidades, transformaram-se em estacionamentos, bingos, supermercados, bancos e templos religiosos (TAVARES, 2010). Este fato pode ser observado na cidade de Novo Hamburgo, onde a partir de 1976, seus quatro cinemas de rua começaram a fechar as portas. A decadência dos cinemas de rua ainda foi consolidada pela inauguração do primeiro shopping center da cidade, em 1991, que atualmente conta com um complexo multiplex com cinco salas, que possuem capacidade entre 137 a 243 espectadores, contabilizando, no total, 837 lugares. Após o fechamento dos cinemas, os respectivos prédios passaram a abrigar lojas e templos religiosos. O Cine Lumière, fez sua última exibição no dia 12 de setembro de 1982, foi alugado pela empresa Grazziotin, e posteriormente vendido para uma igreja neopentecostal, proprietária atual do prédio. Visto que o Cine Lumière possibilitou reunir e divertir a população no passado, buscou-se através de uma nova abordagem para o cinema, atender a demanda de entretenimento e cultura da numerosa e eclética população do presente. A seguir, será apresentada a metodologia e as etapas de realização do projeto.

\subsection{Metodologia e desenvolvimento do projeto}

Como método para esse projeto optou-se pelo modelo do Diamante Duplo (Double Diamond), processo direcionado ao design de serviços desenvolvido pelo Design Council (2005). O procedimento consiste no diamante da esquerda com as etapas que compreendem pesquisa, interpretação de dados e geração de conceitos: Descobrir (Discover) e Definir (Define). O diamante da direita consiste no desenvolvimento do projeto propriamente com as etapas Desenvolver (Develop) e Distribuir (Deliver) (FRAGA; SCALETSKY, 2011). Para complementar as ferramentas disponíveis na etapa Descobrir (Discover) do Diamante Duplo, foram acrescidos os procedimentos do metaprojeto apresentados por De Moraes (2010), com a finalidade de adicionar mais informações na etapa inicial de pesquisa. Assim, a versão adaptada para este trabalho dos dois métodos citados pode ser vista na figura a seguir. 
Figura 02 - Método Projetual

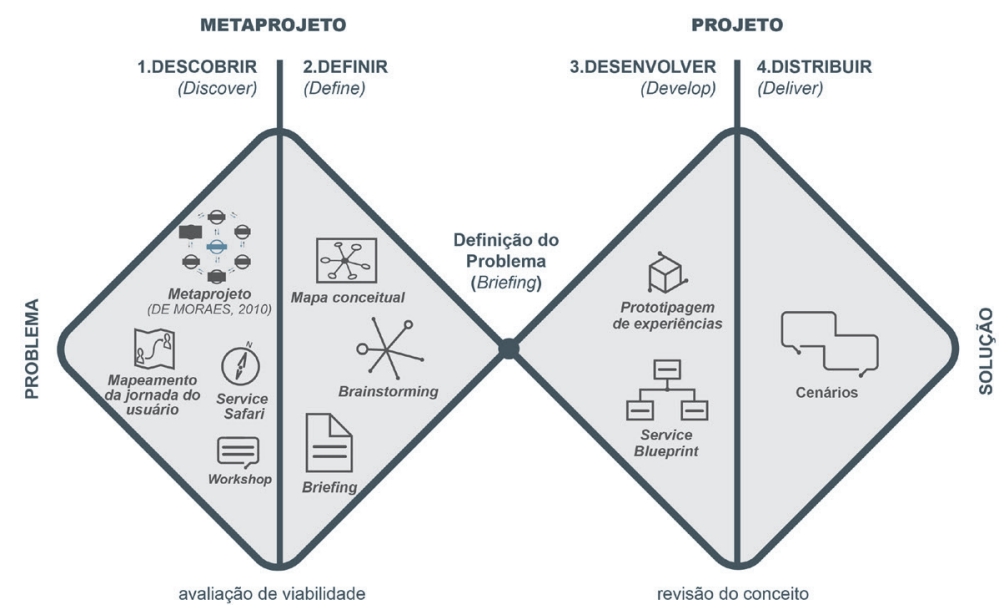

Fonte: elaborado pela autora, adaptado de Design Council (2005).

Na etapa Descobrir (Discover), o uso do Mapeamento da Jornada do usuário - representação visual do progresso do consumidor através do serviço - e do Service Safari - observação e registro dos usuários e do ponto de venda possibilitou a análise de dois cinemas de rua existentes na cidade de Porto Alegre - o Instituto Naum Turquenitch (Instituto NT) e o Guion Center - e o cinema localizado no Centro de Educação Integrada (CEI), no município de Campo Bom. Também foram analisados os cinemas dos shopping centers da região metropolitana de Porto Alegre no modelo multiplex: Cinemark, Cinesystem e GNC Cinemas. Essa análise teve a intenção de avaliar os serviços oferecidos, a fim de identificar oportunidades para o projeto.

De modo geral, as análises apontaram que o ritmo do cinema de rua é diferenciado em relação ao modelo encontrado no shopping center. Percebe-se a ausência de filas devido ao público reduzido, o que contribui para um melhor atendimento por parte dos funcionários. Além disso, ressalta-se a variedade de itens nos cafés e bomboniéres dos cinemas de rua, em contraponto ao cardápio limitado dos que são encontrados nos shopping centers. Por outro lado, enquanto cinemas multiplex contam com investimentos na estrutura e divulgação, os cinemas de rua carecem de melhorias no espaço e na comunicação. Ainda assim, o estudo da experiência nos cinemas analisados nessa etapa justifica a proposta de pesquisa e confirmam as hipóteses lançadas inicialmente.

O workshop, também realizado na primeira etapa de projeto, teve como objetivo auxiliar na busca de soluções e gerar conceitos para o projeto através de pessoas que representassem diferentes contextos e expressassem diferentes opiniões e expectativas (FRAGA; SCALETSKY, 2011). A atividade foi realizada em dois dias e, nos dois momentos, inicialmente foram fornecidas informações prévias e comunicou-se a intenção do estudo aos participantes através de uma apresentação. Posteriormente, foram lançadas três perguntas elaboradas a

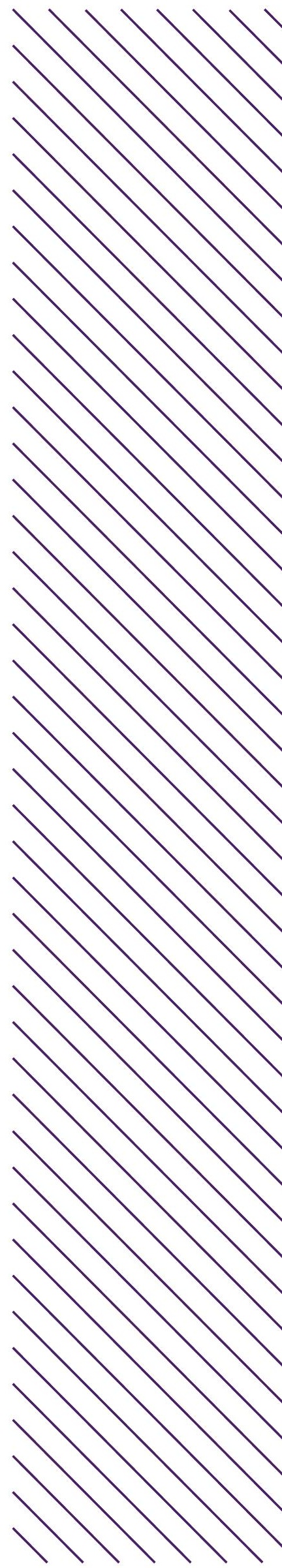


partir dos objetivos desse trabalho para reflexão e debate: a) Como você avalia 0 atendimento do cinema atualmente? b) Quais diferenciais um cinema de rua poderia apresentar em relação aos cinemas dos shoppings? c) Como um cinema de rua poderia contribuir para o fortalecimento da identidade cultural da cidade?

No primeiro dia de workshop, após discutirem sobre as perguntas, os participantes foram convidados a descrever suas ideias através de uma ficha elaborada a partir do modelo da organização alemã Service Design Berlin . O material era composto de três perguntas: qual é a ideia, para que serve e como funciona? No final, havia espaço para um esboço, de acordo com a necessidade. Depois de vinte minutos, todas as ideias descritas foram expostas e cada uma delas foi discutida pelos participantes. Com o término da discussão, através de uma matriz elaborada previamente, o grupo estabeleceu quais serviços sugeridos nas fichas poderiam ser oferecidos em determinados pontos de contato do atendimento do cinema. O grupo sugeriu serviços relacionados à escolha interativa de filmes, ingressos temáticos, cardápio personalizado e sala de espera com atividades de interação. Já no segundo dia de workshop, os convidados formaram três grupos, e, para o levantamento das percepções e ideias acerca da temática, foi utilizada a ferramenta 635 . Os dois momentos trouxeram diversas ideias de serviços para o cinema que foram selecionadas e subdividas nas seguintes categorias: Retrô, Alternativo, Familiar, Conforto, Dentro da Sala, Cardápio, Ambientação, Publicidade, Promoções e Ações. Os resultados contribuíram para elaboração do conceito e das propostas de serviços para o cinema, que foram definidos na etapa seguinte do trabalho.

Desse modo, o mapa conceitual elaborado na etapa Definir (Define) foi construído tendo em vista como as propostas de serviços para o cinema poderiam gratificar os sentidos. O mapa conceitual elaborado de acordo com a fundamentação teórica e com as ideias sugeridas nos workshops pode ser visto abaixo.

Figura 03 - Mapa Conceitual

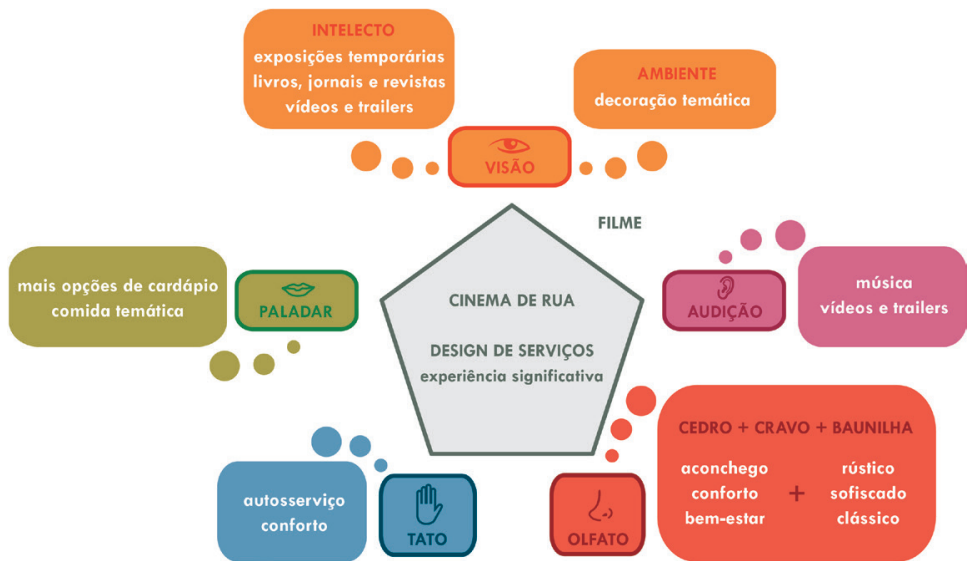

Fonte: elaborado pela autora. 
Como estímulo à visão pretendeu-se compor um ambiente convidativo que propicie a permanência agradável no espaço e que oportunize a socialização dos frequentadores. Também seriam contemplados estímulos visuais relacionados ao intelecto como a disponibilização de livros, revistas e jornais, assim como, um espaço destinado a exposições variadas e exibição de vídeos e trailers de filmes. Além dos vídeos, com o uso de música temática intenciona-se conduzir o público a uma experiência auditiva envolvente.

Visto que, a bomboniére dos cinemas dos shopping centers, de forma geral, não apresenta variadas opções de cardápio, para esse cinema de rua, entende-se como diferencial propor opções de cardápio diversificadas. Bem como, promover conforto e engajar o público criativamente. Para tanto, sugerese o autosserviço como uma alternativa para amenizar o efeito negativo das filas da bilheteria e da bomboniére, e fazer com que os clientes participem ativamente na construção da experiência de serviço.

Com base nos conceitos estabelecidos para esse projeto, buscou-se sugerir de que modo a experiência do cinema em estudo pode agradar também o olfato dos espectadores, tendo em vista que não é apenas o aroma de pipoca que pode caracterizar uma sala de exibição. Para tanto, foram estabelecidos valores que representam a proposta do ambiente do cinema, tais como, rústico, sofisticado, clássico, conforto, bem-estar e aconchego. Com isso, foram selecionados aromas que remetessem a esses valores, como o cheiro de madeira e doces. Desse modo, sugere-se como aroma para o ambiente do cinema uma combinação de cedro, baunilha e cravo.

Nessa etapa do trabalho também foi elaborado o briefing que consiste em uma definição clara do desafio fundamental ou problema a ser resolvido. Para esse projeto, o briefing compreende as seguintes especificações: a) Necessidade; b) Objetivo; c) Público-alvo; d) Conceito; e) Informações sobre o cinema.

A partir do reconhecimento do ambiente atual do cinema e das possibilidades de serviços apresentadas na etapa anterior, através da ferramenta de brainstorming, objetivou-se construir uma experiência integrada na trajetória entre os pontos de contato. Nesse contexto, iniciou-se o zoneamento do espaço com a finalidade de apresentar opções de serviços para o atendimento do cinema, bem como seriam dispostos os ambientes em seu interior. A proposta final pode ser vista na imagem a seguir.

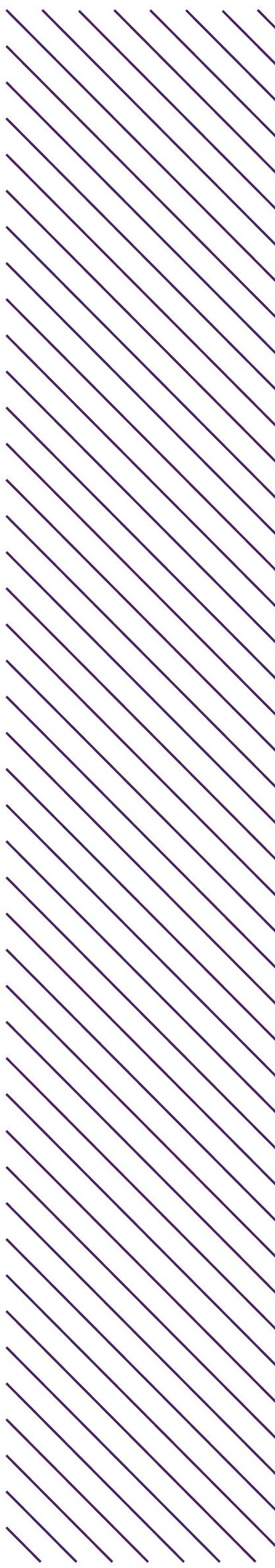


Figura 04 - ambientes propostos para o Cine Lumière

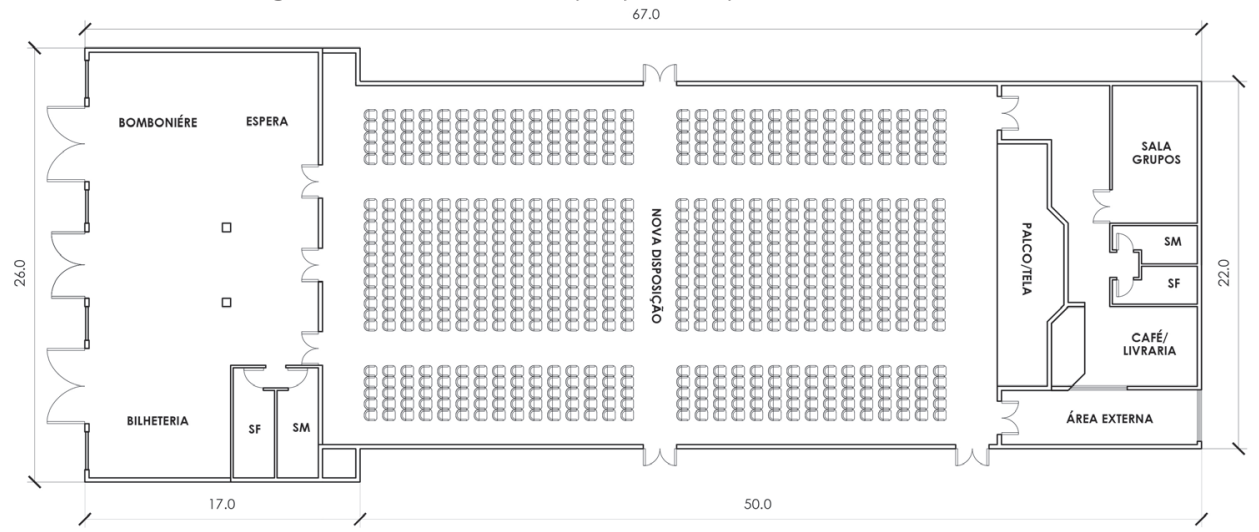

Fonte: elaborado pela autora.

$\mathrm{Na}$ etapa de desenvolvimento (Develop), foram apresentados os serviços que serão articulados entre os ambientes com o auxílio da ferramenta Service Blueprint. O Service Blueprint é o mapa de processos que especifica como o serviço deve funcionar, descrevendo todos os processos, objetos, pessoas e canais envolvidos no serviço. Essa informação é disposta por ordem de ocorrência e estruturada visualmente para fácil navegação e compreensão (PINHEIRO e ALT, 2012). Para especificar os serviços para o cinema em estudo, o Blueprint foi estruturado em três macro etapas: a) antes da sessão, b) esperando a sessão fora e dentro da sala e c) depois da sessão.

Figura 05 - Blueprint

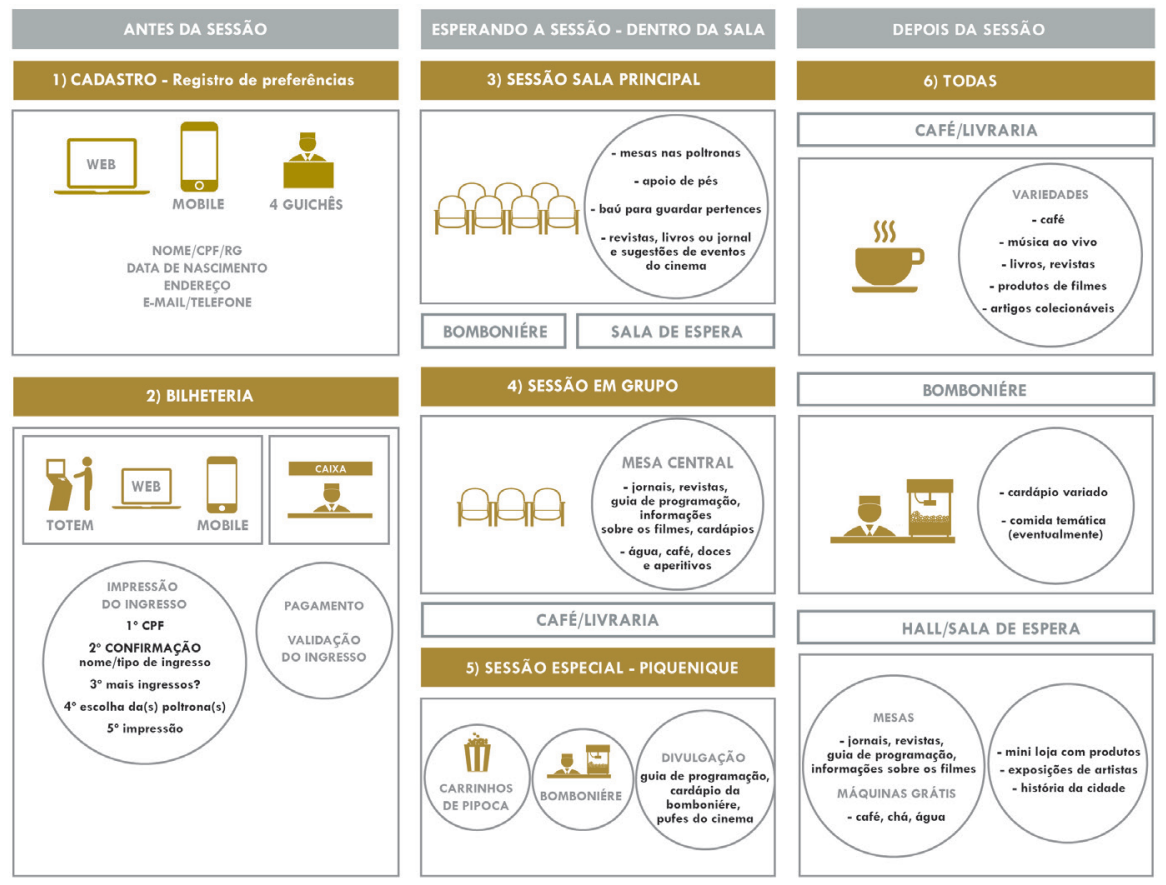

Fonte: elaborado pela autora. 
Para demonstrar visualmente como seriam os serviços propostos, foram desenvolvidos protótipos e cenários na etapa final do projeto. Os cenários têm como finalidade contar a história de uso de um determinado serviço através de textos e imagens. A seguir, a descrição detalhada de cada interação sugerida no Blueprint.

O primeiro contato que o cliente terá com o serviço será através de um cadastramento que consiste no fornecimento de dados gerais, a fim de registrar suas preferências no sistema do cinema. Essas informações serão úteis para a realização de eventos personalizados, descontos e para efetuar a compra dos ingressos. $\mathrm{O}$ cadastramento pode ser realizado online ou em um dos quatro guichês no hall de atendimento (1). Após realizar o cadastramento o cliente pode escolher a exibição que deseja assistir e realizar a compra e a impressão através do totem de autoatendimento, disposto abaixo do pôster do filme que deseja assistir. O pagamento pode ser debitado no cartão de crédito ou realizado no caixa da bilheteria onde, o ingresso será validado (2). A compra também pode ser realizada anteriormente online e o ingresso deve ser retirado na bilheteria. Estes procedimentos serão realizados para a exibição na sala principal (3).

Após a compra e a validação do ingresso, o usuário poderá esperar a sessão usufruindo das opções de cardápio da bomboniére e/ou dirigir-se até a área de espera, onde serão realizadas exposições temporárias temáticas. $\mathrm{O}$ espaço conta ainda, com música ambiente e o oferecimento de água, café e chá gratuitos, além de revistas, jornais e livros. Após entrar na sala principal, o público também encontrará mesas para colocar seus pertences e alguns itens para ler enquanto o filme não começa. As poltronas ainda contam com apoio de pés, que também tem a função de baú, onde o espectador poderá guardar objetos. Em algumas sessões especiais poderá ser realizada uma discussão pós-filme com o público.

As sessões da sala para grupos são realizadas através de uma reserva prévia via site, telefone ou e-mail na qual efetua-se o cadastramento dos integrantes do grupo. Nesse espaço as pessoas poderão escolher o filme que será exibido e agendar dia e horário. Os ingressos serão retirados na bilheteria no dia marcado. Dentro da sala, todos poderão degustar alguns petiscos grátis e apreciar alguns itens para leitura dispostos na mesa central. Ou então dirigirse ao café do cinema antes e após a sessão (4).

Visto que o cinema em estudo encontra-se localizado em frente ao calçadão de Novo Hamburgo, foi prevista uma sessão grátis ao ar livre, a fim de divulgar o cinema para a população da cidade. O evento seria realizado uma vez por mês e, na ocasião, as pessoas poderiam fazer um piquenique trazendo seus próprios lanches (5). O cinema ficaria responsável pela exibição de um filme escolhido em votação pelo público e venderia pipoca em carinhos antigos no

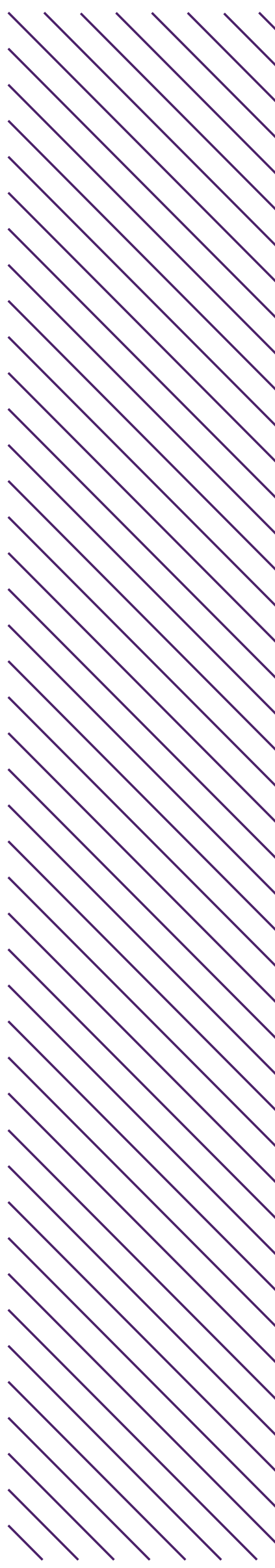


local. A bomboniére também ficaria aberta nesse dia. Após todas as sessões, os espectadores teriam acesso às áreas do café, da bomboniére e da exposição, para que a experiência do filme possa ser estendida através da permanência prolongada no espaço (6). Algumas imagens dos ambientes e serviços para $p$ cinema podem ser vistos na figura 06.

Figura 06 - Fachada, assinatura visual, bilheteria, sala de espera, detalhe da sala principal, sala para grupos e vista do hall de entrada propostas para o Cine Lumière

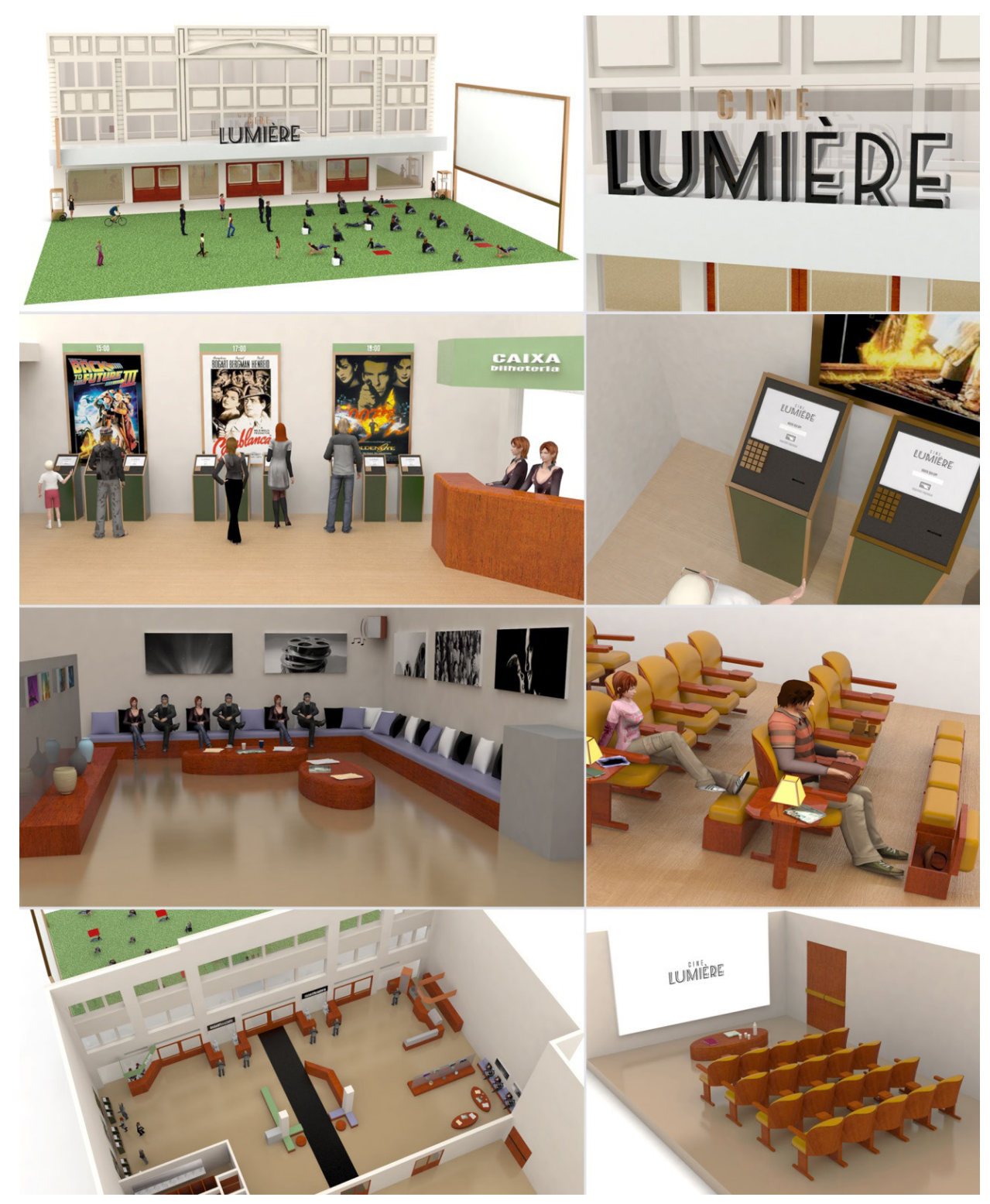

Fonte: elaborado pela autora.

\section{CONCLUSÃO}

Com esse trabalho, objetivou-se tratar o design sob uma abordagem 
mais ampla e complexa, projetando todas as possíveis interações voltadas ao serviço de entretenimento de um cinema. O tema tornou-se um desafio, levando em consideração o caráter intangível da experiência de lazer que não é consubstanciada por bens materiais, e sim, pela apreciação e envolvimento em um evento ou atividade.

A metodologia utilizada no projeto favoreceu a coleta de informações e apontou novas possibilidades para compreender as necessidades dos usuários, como as técnicas de observação no ponto de venda e a realização de workshops. Conforme os autores mencionados nesse estudo, nem sempre através de questionários e entrevistas, as pessoas relatam suas necessidades, de fato. Porém, através de suas ações, ao interagirem com o serviço, demonstram suas verdadeiras necessidades. Assim como nos workshops, com o auxílio de ferramentas para geração de ideias, podem ser obtidos resultados verdadeiramente inspiradores.

Espera-se que o trabalho contribua para o referencial teórico em design de serviços e design para experiência, pois tratam-se de áreas recentes de estudo. Destaca-se ainda nesse trabalho a importância da abordagem sociocultural por meio do design, visto que contempla a revitalização do Cine Lumière, um espaço que representava importante meio de lazer e cultura para a população de Novo Hamburgo - RS. Por meio desta pesquisa, demonstrou-se que o projeto em design é estratégico para a revitalização de espaços urbanos degradados e, como visto neste caso, o designer pode contribuir para uma experiência de qualidade em um ambiente cultural.

\section{REFERÊNCIAS}

COSTA, Filipe Campelo Xavier; Experiências de consumo em gastronomia: como o design pode meter sua colher? In: $8^{\circ}$ CONGRESSO BRASILEIRO DE PESQUISA E DESENVOLVIMENTO EM DESIGN, Anais... São Paulo, out 2008.

DE MORAES, Dijon. Metaprojeto: o design do design. São Paulo, SP: Blucher, 2010.

DESIGN COUNCIL, 2005. Disponível em: <https://www.designcouncil. org.uk/sites/default/files/asset/document/ElevenLessons_Design_ Council\%20(2).pdf>. Acesso em: 23 mar. 2014.

FRAGA, Eliara; SCALETSKY, Celso. Workshops em design: espaços de aprendizagem e geração de conhecimento. In: DESENHANDO O FUTURO | 1ํ CONGRESSO NACIONAL DE DESIGN, Anais... Bento 
Gonçalves, ago 2011. Disponível em: <http://www.desenhandoofuturo. com.br/anexos/anais/gestao_e_metodologia_de_design/workshops_ em_design_espacos_de_aprendizagem_e_geracao_de_conhecimento. pdf>. Acesso em: 23 mar. 2013.

GURGEL, Miriam. Projetando espaços: guia de arquitetura de interiores para áreas comerciais. 3. ed., rev. São Paulo, SP: SENAC São Paulo, 2010.

HEKKERT, Paul. Design Aesthetics: Principles of Pleasure in Product Design. In: PSYCHOLOGY SCIENCE, 48, 2006, p.157-172. Disponível em: <http://www.pabst-publishers.de/psychologyscience/2-2006/06_Hekkert.pdf>. Acesso em: 16 mar. 2014.

IBGE, 2013. Disponível em: <http://cidades.ibge.gov.br/xtras/perfil. php?lang=\&cod mun=431340\&search=riogrande-do-sul|novohamburgo>. Acesso em: 20 out. 2013.

KERN, Paulo Henrique. Ruas \& Praças: Novo Hamburgo: quem é quem. 2. ed. Novo Hamburgo, RS, 2002.

LIMEIRA, Tania M. Vidigal. Tempo livre, lazer e entretenimento. Marketing do entretenimento. São Paulo, SP: SENAC São Paulo, 2008, p. 31-45.

MORITZ, Stefan. Service Design: Practical access to an evolving field. Londres, 2005. Disponível em: <http://stefan-moritz.com/_files/ Practical\%20Access\%20to\%20Service \%20Design.pdf>. Acesso em: 16 mar. 2014.

PINHEIRO, Tennyson; ALT, Luis. Design thinking Brasil: empatia, colaboração e experimentação para pessoas, negócios e sociedade. Rio de Janeiro, RJ: Elsevier, 2012.

RIOS, Igor Goulart Toscano. Design para experiências e customização em massa. In: 1o COLÓQUIO NACIONAL DE DESIGN, Anais... Belo Horizonte, set de 2011. Disponível em: <http://coloquiodesign.com.br/ wp-content/uploads/2011/11/COLOQUIO.DESIGN_Ana is_2011.pdf>. Acesso em: 13 nov. 2013.

ROCHA, Everardo; BARROS, Carla; KARAM, Karine. Diversões perigosas: experiências de entretenimento e limites do consumo. In: REVISTA ALCEU v. 12 - n. 24, jan./jun. 2012, p. 31-47. Disponível em:<http://revistaalceu.com.puc-rio.br/media/Artigo\%203_24.pdf>. Acesso em: 16 mar. 2014. 
SAAB, William George Lopes; RIBEIRO, Rodrigo Martins. Panorama Atual do Mercado de Salas de Exibição no Brasil. Rio de Janeiro: BNDES Setorial, no 12, set. 2000, p. 175-194.

SAVASTANO, Martha. O produto do entretenimento. Marketing do entretenimento. São Paulo, SP: SENAC São Paulo, 2008, p. 47-60.

SCHÜTZ, Liene M. Martins. Novo Hamburgo: sua história, sua gente. 2. ed. 1992.

SILVA, Cristina Ennes da; PUHL, Paula Regina; STRÖHER, Carlos Eduardo. Lazer e sociabilidade em Novo Hamburgo: no escurinho do cinema. In: Esboços: revista do Programa de Pós-graduação em História da UFSC, Florianópolis, SC, v. 16, nํ21, 2009, p. 41-68.

SURI, Jane Fulton. The experience of evolution: developments in design practice. In: THE DESIGN JOURNAL, 6(2):39-48, 2003. Disponível em: <http://ruexperienced.files. wordpress.com/2009/01/suri_ theexperienceevolution.pdf>. Acesso em: 16 mar. 2014.

TAVARES, Francine Silveira. Cinema e patrimônio: o Theatro Guarany de Pelotas/RS. 2010. 154 f. Dissertação (mestrado) - Universidade Federal de Pelotas, Programa de Pós-Graduação em Memória Social e Patrimônio Cultural.

TURNER, Graeme. Cinema como prática social. São Paulo: Summus, 1997.

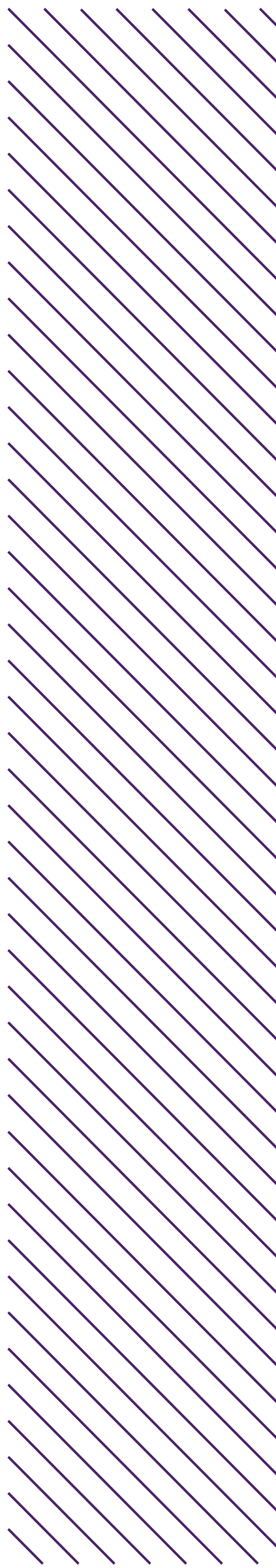

